\title{
Pengembangan Media Evaluasi Hearsmon Berbasis SEL (Social Emotional Learning) dalam Pembelajaran IPA Materi Sistem Pendengaran Bagi Siswa SD
}

\author{
Dyah Aniza Kismiati \\ Alumni Program Pascasarjana Universitas Negeri Yogyakarta \\ email: anizady93@gmail.com
}

\begin{abstract}
This study aims to develop a media evaluation based on monopoly games combined with the values of Social Emotional Learning (SEL) on hearing system material for Grade IV Primary School students. This type of research is a Research and Development (RnD) with ADDIE design (Analysis, Design, Develop, Implement, and Evaluate). The stages carried out for this research are limited to the Development stage. The results of this study are in the form of a monopoly evaluation media, hereinafter referred to as Hearsmon, which contains test instruments related to the hearing system material for grade IV students. The values of Social Emotional Learning (SEL) developed through this media include personal dimensions (self-awareness, self-efficacy, self-management) and social dimensions (respect for others).
\end{abstract}

Keywords: Social Emotional Learning, evaluation media, monopoly games, hearing systems, elementary school students.

\begin{abstract}
Abstrak
Penelitian ini bertujuan untuk mengembangkan media evaluasi berbasis permainan monopoli yang dikombinaikan dengan nilai-nilai Social Emotional Learning (SEL) bagi siswa Sekolah Dasar Kelas IV pada materi sistem pendengaran. Jenis penelitian ini merupakan penelitian Research and Development $(\mathrm{RnD})$ dengan desain ADDIE (Analysis, Design, Develop, Implement, and Evaluate). Tahapan yang dilakukan untuk penelitian ini dibatasi hingga pada tahap Develop (pengembangan). Hasil penelitian ini berupa media evaluasi berbentuk monopoli yang selanjutnya disebut dengan Hearsmon yang didalamnya berisi instrument tes terkait materi sistem pendengaran bagi siswa kelas IV. Adapun nilai-nilai Social Emotional Learning (SEL) yang dikembangan melalui media ini antara lain berupa dimensi personal (self-awareness, self-efficacy, selfmanagement) dan dimensi sosial (respect for others).
\end{abstract}

Kata Kunci: Social Emotional Learning, media evaluasi, permainan monopoli, sistem pendengaran, siswa SD. 


\section{PENDAHULUAN}

Indonesia pada saat ini tengah berhadapan dengan permasalahan internal maupun eksternal dalam bidang pendidikan seperti perubahan sosial dan budaya serta teknologi yang membawa dampak positif maupun negatif bagi siswa.

Pendidikan, secara umum memberikan landasan kuat kepada siswa untuk menjadi Sumber Daya Manusia (SDM) yang mampu berpikir, berperasaan, berkesadaran, bertindak, berperilaku dan beramal sesuai dengan agama yang dianut masing-masing. Pendidikan umum bertujuan memanusiakan manusia (siswa) dan proses pelaksanaannya wajib dilandasi dengan moral yang bermakna seluas-luasnya (Mulyana, 2008). Pada proses pendidikan umum, moral wajib tercermin dalam suasana pembelajaran interaksi edukatifpengembangan materi pembelajaran, penerapan metode dan strategi sampai dengan evaluasi yang diterapkan. Pada pelaksanaan pendidikan umum, moral itu menjadi jiwa, suasana, interaksi edukatif dan tujuannya. Pendidikan umum berupaya secara bermakna dan berkesinambungan menghasilkan SDM yang bermoral bagi semua konteks kehidupan dalam suasana dan kondisi apapun (Sumaatmadja, 2002).

Memasuki era Revolusi 4.0, sektor pendidikan adalah salah satu sektor yang terdampak cukup signifikan, dimana hal ini merupakan tantangan berat bagi guru di Indonesia. Mengutip dari Jack Ma dalam pertemuan tahunan World Economic Forum 2018, pendidikan adalah tantangan besar abad ini. Jika tidak mengubah cara mendidik dan belajar mengajar, 30 tahun mendatang kita akan mengalami kesulitan besar. Pendidikan dan pembelajaran yang sarat dengan muatan pengetahuan mengesampingkan muatan sikap dan keterampilan sebagaimana saat ini terimplementasi, akan menghasilkan peserta didik yang tidak mampu berkompetisi dengan mesin. Dominasi pengetahuan dalam pendidikan dan pembelajaran harus diubah agar kelak anak-anak muda Indonesia mampu mengungguli kecerdasan mesin sekaligus mampu bersikap bijak dalam menggunakan mesin untuk kemaslahatan (Kompasiana: 2019).

Terkait dampak revolusi industri 4.0, ada hal yang harusnya menjadi fokus para guru yakni perkembangan sikap dan emosional siswa. Pada awal tahun 2016, WEF (World Economic Forum) merilis laporan tentang visi baru pendidikan yang berkaitan dengan pembelajaran sosial-emosional atau socialemotional learning (SEL). Laporan dengan Judul "New Vision for Education: Fostering Social and Emotional Learning through Technology" merupakan tindak lanjut dari laporan sebelumnya pada tahun 2015 tentang isu kesenjangan keterampilan atau skills lulusan pada abad ke-21. Dengan kata lain, socialemotional learning merupakan manifestasi dalam mencapai berbagai keterampilan abad ke-21 maupun di era revolusi industri 4.0 (Helaluddin, 2019).

Social Emotional Learning (SEL) menurut Elia et.al (Marc A. Brackett \& Susan E. Rivers, 2012) mengacu pada proses pengintegrasian pemikiran, perasaan, dan perilaku untuk menjadi sadar akan diri sendiri dan orang lain, membuat keputusan yang bertanggung jawab, serta mengelola sendiri perilaku dan perilaku orang lain. SEL berkaitan dengan kecerdasan emosi seperti yang 
didefinisikan oleh Goleman. Goleman (2001) menjelaskan bahwa kecerdasan emosi dapat didefinisikan dalam empat dimensi, yaitu antara lain :

1. Self-awareness yaitu kemampuan manusia untuk secara akurat memahami diri sendiri dan tetap sadar terhadap emosi diri ketika emosi muncul, termasuk tetap mempertahankan cara manusia dapat merespons situasi tertentu dan orang-orang tertentu di dalamnya terdapat kesadaran emosi (emotional awareness), penilaian diri yang akurat (accurate self-assessment), dan kepercayaan diri (self confidence);

2. Social Awareness, adalah kemampuan manusia untuk secara tepat menangkap emosi orang lain dan mengerti apa yang benar-benar terjadi, dapat diartikan memahami apa yang orang lain pikirkan dan rasakan walaupun tidak merasakan yang sama, di dalamnya terdapat: empati, orientasi pelayanan (service orientation), kesadaran berorganisasi (organizational awareness);

3. Self Management, adalah kemampuan untuk menggunakan kesadaran emosi manusia untuk tetap fleksibel dan secara positif mengarahkan perilaku diri manusia itu sendiri, yang berarti mengelola reaksi emosi manusia itu sendiri kepada semua orang dan situasi, di dalamnya terdapat: kontrol emosi diri (emotional self-control), dapat dipercaya (trustworthiness), teliti (conscientiousness), kemampuan beradaptasi (adaptability), dorongan berprestasi (achievement drive), inisiatif;

4. Relationship Management, kemampuan untuk menggunakan kesadaran emosi manusia dan emosi orang lain untuk mengelola interaksi yang berhasil, termasuk berkomunikasi dengan jelas dan efektif untuk mengatasi konflik, yang didalamnya terdapat memajukan orang lain (developing others), dapat mempengaruhi (influence), komunikasi (communication), manajemen konflik (conflict management), dapat memimpin (visionary leadership), catalyzing change, membangun ikatan (building bonds), kerjasama dan berkolaborasi (teamwork and collaboration).

Seperti yang telah dikemukakan dalam laporan WEF, ada beberapa jenis keterampilan yang harus dikuasai oleh lulusan atau peserta didik dalam menghadapi era disruptif ini. Secara garis besar, ada tiga kelompok keterampilan abad ke21, yaitu: (1) foundational literacies, (2) competencies, dan (3) character qualities (World Economic Forum, 2015). Keterampilan foundational literacies terdiri atas literasi dasar, literasi numerikal, literasi sains, literasi TIK (Teknologi Informasi \& Komunikasi), literasi finansial, dan literasi budaya kewarganegaraan (World Economic Forum, 2015). Keterampilan berikutnya yang harus dikuasai oleh lulusan abad ke-21 adalah competencies, yaitu: (1) berpikir kritis atau keterampilan problem-solving, (2) kreativitas, (3) komunikasi, dan (4) kolaborasi. Sedangkan character qualities yang dituju pada abad ke-21 adalah: (1) rasa ingin tahu, (2) inisiatif, (3) adaptif, (4) kepemimpinan, (5) kepedulian sosial dan budaya, dan (5) ketekunan (World Economic Forum, 2015).

Berkaitan dengan pembelajaran sosial-emosional (SEL), 
World Economic Forum (2016) menjabarkan bahwa diperlukan proses pembelajaran melalui socialemotional learning. Dengan penerapan social-emotional learning di sekolah, diharapkan siswa memiliki berbagai keterampilan yang dibutuhkan dalam mencapai keberhasilan pada masa yang akan datang. Tentunya dalam hal ini, guru pun mendapatkan tantangan yang lebih besar lagi dalam mengelola kreativitas agar tuntutan revolusi industri 4.0 di bidang pendidikan dapat terpenuhi dan sejalan dengan sistem pembelajaran yang melibatkan social-emotional learning terutama dalam penyampaian materi-materi saintifik seperti IPA.

Belajar IPA merupakan kegiatan pembelajaran untuk menyelidiki proses-proses yang terjadi pada objek kajian biologi, yaitu makhluk hidup. Sebagai sebuah penemuan (inquiry), fakta dan konsep biologi bersumber dari investigasi yang dilakukan pada waktu dan kondisi tertentu. Karena IPA merupakan ilmu yang dinamis maka pembelajaran IPA dapat dipadukan dengan teknologi yang dapat meningkatkan kompetensi peserta didik dalam proses pembelajaran.

Ketercapaian kompetensi untuk berbagai jenjang pendidikan tentulah berbeda, terutama untuk siswa Sekolah Dasar (SD). Pada jenjang SD/MI Kelas I, II, dan III (kelas rendah) muatan Sains diintegrasikan pada mata pelajaran Bahasa Indonesia, sedangkan di Kelas IV, V, dan VI (kelas tinggi) IPA menjadi mata pelajaran yang berdiri sendiri tetapi pembelajarannya menerapkan pembelajaran tematik terpadu.

Dalam Permendikbud No. 37 tahun 2018, dipaparkan kompetensi
Inti dan Kompetensi Dasar menjadi tuntutan kurikulum bagi siswa SD/MI yang berada di kelas rendah (Kelas IIII) dan kelaa atas (IV-VI). Perbedaan yang paling mendasar dari kedua jenis jenjang tersebut adalah pada bagian kemampuan dalam menyelesaikan masalah (problem solving), pengambilan keputusan, dan penggunaan teknologi dan dampaknya dalam pembelajaran.

Siswa Sekolah Dasar (SD) menurut Piaget (2010), termasuk ke dalam tahap perkembangan kognitif operasional konkret, dimana pembelajaran akan bermakna apabila disampaikan dengan menggunakan media pembelajaran yang menarik, terutama untuk materi IPA yang terkait dengan sistem-sistem yang terjadi pada tubuh manusia, salah satunya adalah sistem pendengaran.

Materi seperti sistem pendengaran bila disampaikan secara monoton saja (hanya dengan metode ceramah) tentunya kurang diminati oleh siswa SD. Oleh karenanya, diperlukan inovasi pendidikan dalam hal metode dan media pembelajaran. Reigeluth (2011) memaparkan inovasi pendidikan dalam metode dan media pembelajaran mencakup rumusan tentang pengorganisasian bahan ajar, strategi penyampaian dan pengelolaan kegiatan dengan memperhatikan tujuan, hambatan, dan karakteristik siswa sehingga diperoleh hasil yang efektif, efisien, dan menimbulkan daya tarik pembelajaran. Salah satu inovasi pendidikan yang dapat digunakan adalah penggunaan permainan tradisional dalam pembelajaran, seperti permainan monopoli.

Berdasarkan hasil penelitian

oleh Gumilang (2019) dan Vikagustanti dkk (2014), media pembelajaran IPA yang berbasis 
permainan monopoli terbukti dapat menciptakan suasana belajar yang nyaman dan menyenangkan sehingga minat siswa dalam pembelajaran IPA meningkat yang membawa pengaruh pada peningkatan hasil belajar. Dengan demikian, pengembangan media pembelajaran dan evaluasi permainan monopoli penting untuk dikembangkan untuk meningkatkan ketertarikan, minat dan hasil belajar siswa SD, terlebih dengan mengkombinasikan nilai-nilai Social Emotional Learning (SEL) dalam penyusunan dan pelaksanaannya.

\section{METODE PENELITIAN}

Jenis penelitian ini merupakan penelitian Research and Development (R\&D) dengan model ADDIE (Analysis, Design, Development, Implementation, and Evaluation). Namun, dalam penelitian ini, peneliti melakukan pengembangan media hingga pada tahap Development saja dan belum melakukan uji coba (implementasi). Paparan mengenai model ADDIE dikembangkan oleh dalam penelitian ini yaitu:

\section{Analysis}

Pada tahap ini, kegiatan utama yang dilakukan adalah menganalisis perlunya pengembangan model atau metode pembelajaran baru (Dick and Carry, 1996). Dari hasil wawancara yang dilakukan terhadap guru sekolah dasar swasta di Yogyakarta (SDIA 55 Yogyakarta), pembelajaran IPA terkait sistem pendengaran disampaikan melalui metode ceramah dan juga penggunaan powerpoint sebagai media pembelajaran. Hal ini dirasakan belum cukup untuk memberikan pengalaman belajar kepada siswa, sebab siswa memiliki keingintahuan yang tinggi terhadap materi sistem pendengaran. Capaian dari tahapan ini adalah diperlukan suatu media pembelajaran yang sekaligus dapat menjadi media evaluasi yang menarik bagi siswa. Dengan memperhatikan tingkat perkembangan kognitif siswa dan jenjang pendidikan, maka media berbentuk permainan tentu akan sangat diminati oleh siswa SD. Oleh karenanya, peneliti berinisiatif untuk mengembangkan media berbasis permainan. Selain itu, dalam tahapan ini pula dipilih apek kecerdasan emosional dalam SEL (Socio Emotional Learning) yang ingin dikembangkan oleh guru. Berdasarkan hasil diskusi dengan guru pada sekolah terkait, sasaran SEL yang ingin dikembangkan adalah pada dimensi personal dan sosial dalam pembelajaran. Oleh karena itu, peneliti berusaha untuk memasukkan aspek self-awareness (keberanian) dan self-management (manajemen diri sendiri) untuk mengembangkan dimensi social serta aspek respect for others dalam dimensi sosial.

2. Design

Menurut Branch (2009), tujuan dari tahap Design ini adalah untuk memverifikasi hasil pembelajaran yang diinginkan dan menyesuaikan metode tes yang digunakan. Proses 
awal yang dilaksanakan untuk memulai tahap Design adalah merumuskan tujuan pembelajaran yang spesifik, measurable, applicable, dan realistic. Spesifik, dapat diartikan sebagai sebuah target yang jelas dan utama. Measurable yaitu tujuan atau target pembelajaran dapat diukur keberhasilannnya yang dilihat dari kemajuan berdasarkan kondisi awal. Applicable yakni mudah diaplikasikan atau diterapkan kepada subjek, serta realistic yaitu sesuai dengan kondisi yang ada. Tujuan pembelajaran yang ditetapkan sesuai dengan Kompetensi Inti dan Kompentesi Dasar mata pelajaran IPA bagi siswa SD/MI berdasarkan Permendikbud No 37 tahun 2018 adalah "Menerapkan sifat-sifat bunyi dan keterkaitannya dengan indera pendengaran". Pada tahapan design ini, media yang dikembangkan oleh peneliti berbasis pada permainan monopoli. Pertimbangan yang digunakan dalam memilih jenis permainan tersebut adalah karena target siswa dalam hal ini adalah siswa kelas IV. Permainan monopoli termasuk suatu permainan yang relatif digemari anak dan mudah dalam memainkannya meskipun dengan sedikit taktik atau siasat. Untuk mewujudkannya, peneliti membuat rancangan modifikasi set permainan monopoli dalam bentuk storyboard dengan memasukkan materi sistem pendengaran.

\section{Development}

Tahap Development atau tahap pengembangan ini bertujuan untuk mengembangkan dan memvalidasi sumber-sumber pembelajaran yang digunakan (Branch, 2009). Langkah pengembangan meliputi kegiatan membuat, membeli dan memodifikasi bahan/ media pembelajaran atau dapat dijabarkan bahwa pada tahapan ini berisi kegiatan realisasi rancangan produk atau storyboard yang sebelumnya sudah dibuat dengan cara menyusun kerangka konseptual penerapan model/ metode pembelajaran baru dan direalisasikan menjadi produk yang siap diimplementasikan yaitu produk Hearsmon (Hearing System Monopoly). Tahap development atau pengembangan ini adalah tahap terakhir yang dilakukan dalam penelitian ini.

\section{HASIL DAN PEMBAHASAN}

Penelitian Pengembangan Media Evaluasi Hearsmon Berbasis SEL (Social Emotional Learning) dalam Pembelajaran IPA Materi Sistem Pendengaran Bagi Siswa SD bertujuan untuk mengembangkan media evaluasi berbasis permainan monopoli yang dikombinasikan dengan nilai-nilai Social Emotional Learning (SEL) bagi siswa Sekolah Dasar Kelas IV pada materi sistem pendengaran.

Media permainan monopoli IPA selain unik dan menarik juga membuat mereka merasa lebih semangat dan percaya diri untuk belajar IPA karena membuat situasi pembelajaran menjadi lebih 
menyenangkan (Firdaus dkk, 2014). Media permainan monopoli berfungsi sebagai sarana pembelajaran yang dapat digunakan oleh guru dalam proses belajar mengajar. media pembelajaran ini memiliki konsep belajar sambil bermain agar motivasi siswa dalam belajar IPA. Dengan penggunaan media pembelajaran permainan monopoli siswa akan lebih banyak beraktivitas dan pembelajaran akan menjadi lebih aktif, inovatif, kreatif,efektif, dan menyenangkan (Irwan, 2017).Berdasarkan penelitian Irwan (2017) juga diketahui bahwa penggunaan permainan monopoli sebagai media pembelajaran dapat meningkatkan minat dan motivasi siswa untuk belajar, meningkatkan pemahaman siswa dan mengefesienkan waktu dalam mengajar.

Hearsmon (Hearing System Monopoly) sistem pendengaran dirancang dengan bentuk persegi yang berukuran kurang lebih 40 x 40 $\mathrm{cm}$. Papan monopoli ini terbuat dari kertas tebal yang terdiri dari empat puluh petak. Sama halnya dengan monopoli pada umumnya, pada tiap petak terdapat nama negara namun gambar-gambar yang ada di petak adalah gambar-gambar yang terkait materi sistem pendengaran. Di bagian tengah media terdapat gambar utama yang berupa gambar struktur sistem pendengaran manusia. Gambar struktur sistem pendengaran manusia yang ada dibagian tengah dibuat dalam ukuran yang besar agar siswa mudah mengingat struktur sistem pendengaran manusia. Berikut ini adalah deskripsi papan permainan Hearsmon dan aturan dalam memainkan Hearsmon:

a. 22 petak dibagi menjadi delapan kelompok berwarna dengan masing-masing dua atau tiga petak. Seorang pemain harus menguasai satu kelompok warna sebelum ia boleh membeli rumah atau hotel.

b. 4 stasiun kereta. Pemain memperoleh sewa lebih tinggi bila ia memiliki lebih dari satu stasiun. Tapi di atas stasiun tidak boleh dibangun rumah atau hotel.

c. 2 perusahaan, yaitu perusahaan listrik dan perusahaan air. Pemain memperoleh sewa lebih tinggi bila ia memiliki keduanya. Rumah dan hotel tidak boleh dibangun di atas perusahaan.

d. Petak-petak Dana Umum dan Kesempatan. Pemain yang mendarat di atas petak ini harus mengambil satu kartu dan menjalankan perintah di atasnya.

Hearsmon dilengkapi dengan perlengkapan penunjang seperti dua buah dadu lempar, satu set kartu dana umum, satu set kartu kesempatan, serta kartu hak milik. Kartu dana umum dan kartu kesempatan berisi daftar pertanyaan mengenai sistem pendengaran manusia yang terkait dengan bunyi dan pendengaran, sifat bunyi, telinga dan bagian-bagiannya serta cara merawat organ telinga. Komponen-komponen inilah yang dapat digunakan sebagai alat evaluasi untuk mengetahui pemahaman siswa terhadap materi sistem pendengaran. Cara memainkan media evaluasi ini juga tergolong mudah. Hearsmon dapat dimainkan minimal oleh dua orang siswa dan maksimal empat hingga lima orang siswa.

Bila siswa yang sedang mendapat giliran bermain tidak bisa menjawab pertanyaan yang ada di dalam kartu dana umum maupun kesempatan, maka pertanyaan dapat dijawab dan didiskusikan dalam satu kelompok bermain tersebut. Menunggu giliran bermain tanpa 


\section{Kismiati}

mendahului teman akan melatih siswa dalam mengembangkan Social Emotional Learning (SEL) yaitu pada aspek menghormati orang lain (Respect for Others). Permainan seperti ini juga membutuhkan pengelolaan diri yang baik agar disiplin dan menahan emosi agar dapat menang dengan jujur.

Pembuatan papan monopoli dilakukan dengan menggunakan bantuan komputer. Desain gambar terkait materi system pendengaran diambil dari website atau internet, lalu dicetak pada kertas Ivory ukuran A3. Untuk pembuatan Kartu Dana Umum dan Kesempatan juga hampir sama, hanya saja Kartu Dana Umum dan Kesempatan dicetak pada kertas BC lalu digunting sesuai dengan bentuknya. Hasil akhir produk media evaluasi Hearsmon ditujukkan pada Gambar 1, 2, 3 dan 4 berikut ini.

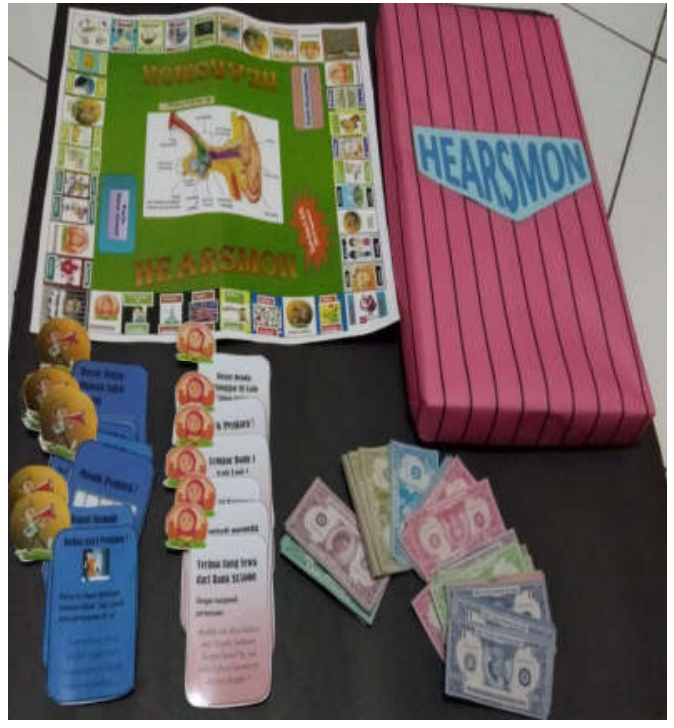

Gambar 1. Set media Hearsmon

(Hearing System Monopoly)

(Sumber: Dokumentasi Dyah Aniza Kismiati, 2019)

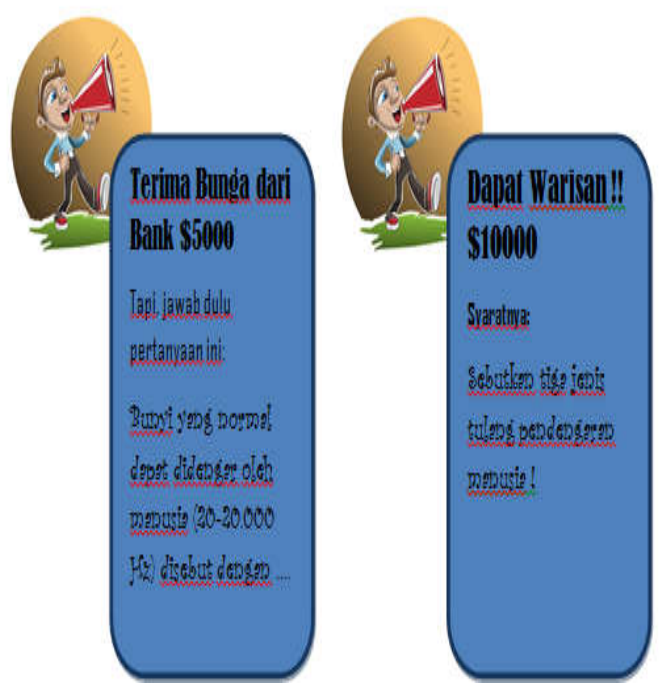

Gambar 2. Desain kartu dana umum Hearsmon

(Sumber: Dokumentasi Dyah Aniza Kismiati, 2019)

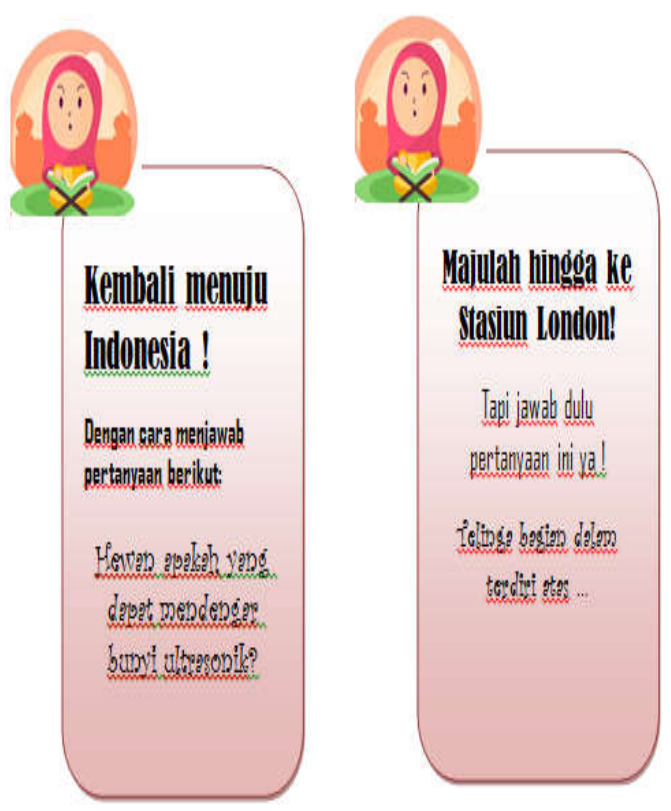

Gambar 3. Desain kartu kesempatan Hearsmon

(Sumber: Dokumentasi Dyah Aniza Kismiati, 2019) 


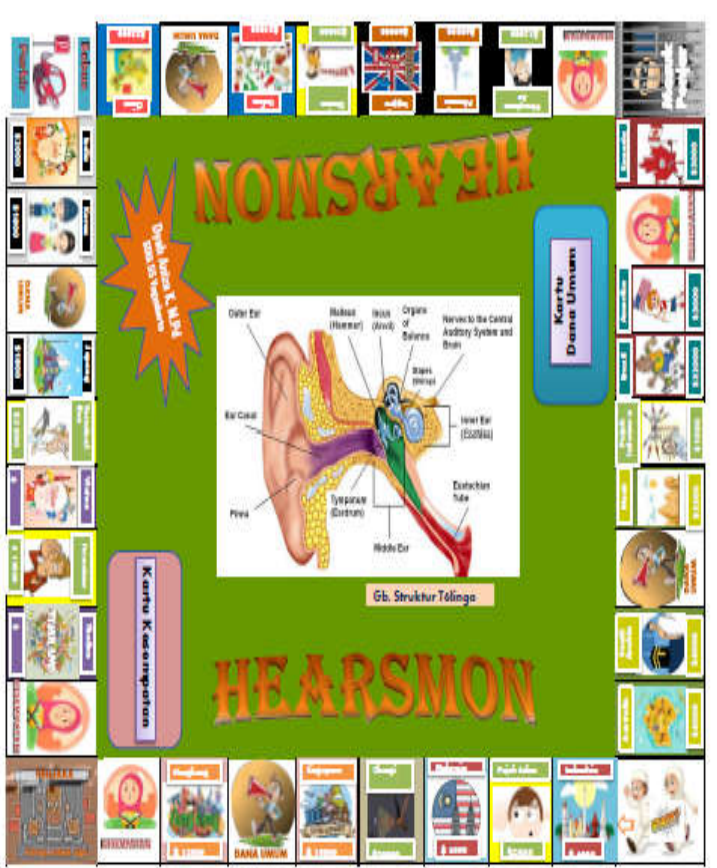

Gambar 4. Papan permainan media Hearsmon

(Sumber: Dokumentasi Dyah Aniza Kismiati, 2019)

Berbeda halnya dengan
monopoli biasa, pada papan
Hearsmon berisi gambar-gambar terkait dengan materi bunyi, struktur telinga, mekanisme mendengar maupun cara-cara merawat kebersihan telinga. Selain itu, pada kartu kesempatan dan dana umum berisi daftar pertanyaan terkait materi sistem pendengaran. Terkait dengan Social Emotional Learning (SEL), berikut ini adalah beberapa kompetensi yang dapat dicapai dengan menggunaaan media Hearsmon yaitu:

a. Pada dimensi kompetensi personal Self-awareness: kompetensi yang dicapai adalah recognizing strength (mengenali kelebihan diri) yang terintegrasi dengan materi cara merawat telinga, yang mana siswa dapat membedakan hal-hal positif yang dapat dilakukan secara berkelanjutan demi kebaikan dirinya. Selain itu kompetensi selfefficacy dengan indicator feeling challenged with a difficult task juga dapat tercapai dimana siswa merasa tertantang untuk menyelesaikan pertanyaanpertanyaan sulit yang ada pada kartu Kesempatan dan Dana Umum.

b. Self-management: kompetensi yang dicapai adalah self-dicipline (disiplin diri) yaitu bagaimana siswa dapat mengontrol emosinya ketika mendapatkan hal yag baik (keuntungan) ataupun ketika mendapatkan hukuman. Kompetensi lain yang dapat tercapai adalah self motivation yaitu optimis diri, percaya bahwa dirinya dapat menyelesaikan segala tugas yang ada dalam Hearsmon dan tidak mudah menyerah.

c. Dimensi kompetensi sosial

Kompetensi yang dapat tercapai pada dimensi ini adalah Respect for others. Hearsmon tidak akan dapat dimainkan sendiri, oleh karenanya, beberapa siswa akan bergabung untuk memainkannya. Setiap siswa harus sabra menanti gilirannya untuk memainkan dadu dan menghargai lawan yang sedang bermain.

Setiap media pembelajaran tentunya memiliki kelebihan dan kelemahan, begitu pula dengan Hearsmon. Berikut ini adalah beberapa kelebihan dan kelemahan media Hearsmon pada aktivitas pembelajaran yang ditunjukkan dalam Tabel 1. 


\section{Kismiati}

Tabel 1. Kelebihan dan kelemahan media pembelajaran Hearsmon

\begin{tabular}{|l|l|l|}
\hline No & \multicolumn{1}{|c|}{ Kelebihan } & \multicolumn{1}{|c|}{ Kelemahan } \\
\hline 1 & $\begin{array}{l}\text { Simple } \\
\text { Proses } \\
\text { pembuatannya } \\
\text { sederhana }\end{array}$ & $\begin{array}{l}\text { Tidak dapat } \\
\text { dimainkan secara } \\
\text { individual } \\
\text { (minimal } \\
\text { orang) }\end{array}$ \\
\hline 2 & $\begin{array}{l}\text { Stand alone } \\
\text { tidak tergantung } \\
\text { pada media lain } \\
\text { atau tidak harus } \\
\text { digunakan } \\
\text { bersama-sama } \\
\text { dengan bahan ajar } \\
\text { lain }\end{array}$ & $\begin{array}{l}\text { Hanya digunakan untuk } \\
\text { materi sistem } \\
\text { pendengaran saja }\end{array}$ \\
\hline 3 & $\begin{array}{l}\text { Flexibel dibawa } \\
\text { Mudah dah } \\
\text { dan dipindahkan, } \\
\text { tidak } \\
\text { membutuhkan } \\
\text { banyak tempat } \\
\text { untuk menyimpan }\end{array}$ & $\begin{array}{l}\text { Untuk } \\
\text { memainkannya } \\
\text { dibutuhkan } \\
\text { tempat yang datar }\end{array}$ \\
\hline 4 & $\begin{array}{l}\text { Use friendly } \\
\text { Mudah digunakan } \\
\text { untuk anak SD }\end{array}$ & $\begin{array}{l}\text { Hanya dapat } \\
\text { digunakan untuk } \\
\text { mengevaluasi } \\
\text { konsep } \\
\text { pemahaman }\end{array}$ \\
\hline 5 & $\begin{array}{l}\text { Perawatan dan } \\
\text { pemeliharaannya } \\
\text { relatif mudah }\end{array}$ & $\begin{array}{l}\text { Membutuhkan } \\
\text { waktu } \\
\text { relative lama }\end{array}$ \\
\hline
\end{tabular}

\section{SIMPULAN}

Berdasarkan tujuan dan pembahasan yang telah dipaparkan, maka dapat disimpulkan bahwa media evaluasi Hearsmon yang berbasis pada permainan monopoli terkait materi sistem pendengaran bagi siswa SD kelas IV dikembangkan melalui model pengembangan ADDIE (Analysis, Design, Development, Implementation, and Evaluation). Evaluasi dapat dilakukan selama proses pembelajaran berlangsung sebab kartu dana umum dan kartu kesempatan selain berisi instruksi dalam bermain juga berisi pertanyaan-pertanyaan terkait sistem pendengaran. Adapun pengembangan media evaluasi ini mencapai tahap Development (pengembangan) sehingga menghasilkan produk yang dinilai kualitasnya melalui uji kelayakan produk oleh para ahli media maupun ahli materi.

\section{SARAN}

Adapun saran pengembangan media Hearsmon yang dapat penulis berikan yaitu terkait dengan materi yang digunakan. Materi sistem pendengaran bisa digali lebih dalam kembali sesuai dengan kompetensi dasar yang diharapkan tercapai, sehingga akan muncul variasi soalsoal yang lebih banyak dalam Kartu Kesempatan maupun Dana Umum. Media evaluasi Hearsmon juga divalidasi oleh para ahli sehingga dibutuhkan pula kuesioner penunjang untuk melihat kualitas produk ini sebelum diujicobakan secara terbuka kepada siswa.

\section{DAFTAR RUJUKAN}

Azzahra, Shahnas. (2019). Pengaruh Revousi Industri 4.0 dalam Pendidikan Indonesia. Diakses dari

https://www.kompasiana.com/s hahnazzhr/5cebf01295760e76fc 2c3f34/pengaruh-revolusiindustri-4-0-dalam-pendidikandi-indonesia 
Branch, Robert Maribe. Instructional Design: The ADDIE Approach. New York : Springer Science \& Business Media, LLC. 2009.

Dick, W. and Carey, L. (1990). The Systematic Design of Instruction. (Fourth ed.). United States of America : Harper Collins Publishers.

Firdaus, Zuhri dkk. (2014). Pengembangan Media Pembelajaran Monopoli Ipa materi Sistem Pencernaan Makanan untuk Siswa kelas VIII SMPN 4 Malang. Malang: UM.

Goleman, Daniel. 2000. Emotional Intelligence (terjemahan). Jakata : PT Gramedia Pustaka Utama.

Gumilang, Juwita Retna. (2019). Pengaruh Penggunaan Media Pembelajaran Monopoli Terhadap Hasil Belajar Ipa Siswa Kelas Iii Sd Negeri 1 Gondang. Jurnal Ilmiah Pendidikan IPA STKIP PGRI Tulung Agung Vol. 1 No. 2.

Helaluddin. (2019). Kajian Konseptual Tentang SocialEmotional Learning (Sel) Dalam Pembelajaran Bahasa. Al-Ishlah: Jurnal Pendidikan Vol. 11, No. 1.

Irwan, Dedek. (2017). Pengembangan Media Permainan (Game) Monopoli Pada Pembelajaran Fisika Materi Besaran Dan Satuan Pada Tingkat Sekolah Menengah Pertama (SMP). Skripsi. Banda Aceh:
Universitas Islam Negeri ArRaniry Darussalam.

Marc A. Brackett \& Susan E. Rivers. (2012). Transforming Students' Lives with Social and Emotional Learning. New Haven: Yale University.

Mulyana, D., dan Rakhmat. (2008). Komunikasi Antar Budaya. Bandung: Rosdakarya

Piaget, Jean, \& Barbel Inhelder. (2010). Psikologi Anak, Terj. Miftahul Jannah, Yogyakarta : Pustaka Pelajar.

Reigeluth, C.M. (2011). Desain Instruksional Teori dan ModelModel (Alih Bahasa: Ary Nilandari). Bandung: Alfabeta

Sumaatmadja. (2002). Metodologi Pengajaran Ilmu Pengetahuan Sosial. Bandung: PT. Alumni.

Vikagustanti, Dea Aransa dkk. (2014). Pengembangan Media Pembelajaran Monopoli Ipa Tema Organisasi Kehidupan Sebagai Sumber Belajar Untuk Siswa SMP. Unnes Science Education Journal 3 (2) (2014).

WEF (World Economic Forum). (2016). New Vision for Education: Fostering Social and Emotional Learning through Technology. Geneva Switzerland. 